\title{
Neurocognitive impairment screening in Romanian HCV infected patients
}

\author{
Ioana-Catrinel Cercel ${ }^{1 *}$, Șerban Polli ${ }^{1}$, Oana Streinu-Cercel ${ }^{1,2}$, Anca Streinu-Cercel ${ }^{1,2}$, Adrian Marinescu$^{1}$, \\ Adrian Streinu-Cercel ${ }^{1,2}$ \\ From The 9th Edition of the Scientific Days of the National Institute for Infectious Diseases Prof Dr Matei Bals \\ Bucharest, Romania. 23-25 October 2013
}

\section{Background}

Neurocognitive impairment can occur in HCV infected patients. A series of studies have shown that patients with HCV may experience diminished attention and concentration, or suffer from severe cognitive deficits, such as disorientation and fluctuating consciousness. We performed a study to determine if there are neurocognitive differences or dissimilarities in the quality of life between a control group and a group of HCV infected patients.

\section{Methods}

We assessed patients by applying the EQ-5D-5L questionnaire and the Montreal Cognitive Assessment. EQ-5D-3L comprises the following 5 dimensions: mobility, self-care, usual activities, pain/discomfort and anxiety/depression. Montreal Cognitive Assessment indicates if patients have neurocognitive impairment. All subjects were evaluated with these questionnaires during an appointment with the clinical psychologist.

\section{Results}

We assessed $11 \mathrm{HCV}$ infected patients and 11 controls. The HCV group had ages between 25-58 with a median of $40 \pm 12$ ( 2 retired, 1 doctor, 1 economist, 2 engineers, 1 architect, 1 editor, 1 clerk, 1 financial analyst) and the control group had ages between 26-38, median 30 \pm 4 (7 doctors, 3 nurses and 1 secretary). EQ-5D-5L scores were $85 \pm 10$ percent (min: 65, max: 95 ) in the $\mathrm{HCV}$ group and $95 \pm 7$ percent (min: 85 , max: 100) in the control group. The median MOCA scores were $28 \pm 4$ (min: 19, max: 31 ) in the HCV group and $30 \pm 3$ (min: 22, max: 31 ) in the control group.

\footnotetext{
* Correspondence: catycercel@yahoo.com

${ }^{1}$ National Institute for Infectious Diseases "Prof. Dr. Matei Balş", Bucharest, Romania

Full list of author information is available at the end of the article
}

\section{Conclusion}

At a first look, we identified apparent neurocognitive differences between the two groups but the number of subjects was too low to offer a statistical significance. We intend to evaluate larger groups of patients, and reapply the tests periodically to determine if there are longitudinal changes in the neurocognitive status.

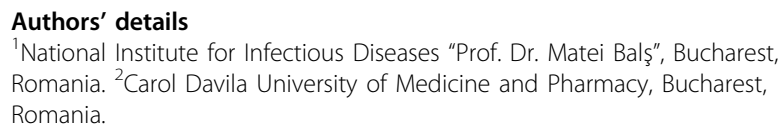

Published: 16 December 2013

doi:10.1186/1471-2334-13-S1-O29

Cite this article as: Cercel et al:: Neurocognitive impairment screening in Romanian HCV infected patients. BMC Infectious Diseases 2013

13(Suppl 1):O29.

\section{Submit your next manuscript to BioMed Central and take full advantage of: \\ - Convenient online submission \\ - Thorough peer review \\ - No space constraints or color figure charges \\ - Immediate publication on acceptance \\ - Inclusion in PubMed, CAS, Scopus and Google Scholar \\ - Research which is freely available for redistribution \\ Submit your manuscript at www.biomedcentral.com/submit}

C Biomed Central

C 2013 Cercel et al; licensee BioMed Central Ltd. This is an Open Access article distributed under the terms of the Creative Commons Attribution License (http://creativecommons.org/licenses/by/2.0), which permits unrestricted use, distribution, and reproduction in any medium, provided the original work is properly cited. 